\title{
En evidensbasert fusjon?
}

\author{
For tiden pågår det en het diskusjon om sykehusfusjoner generelt og storfusjonen Oslo universitetssykehus \\ spesielt. Diskusjonen er mer preget av følelser enn av fakta. Hvordan kan kunnskapsoppsummeringer bidra \\ i denne sammenhengen?
}

\section{Lars Erik Kjekshus}

l.e.kjekshus@medisin.uio.no

Avdeling for helseledelse og helseøkonomi Universitetet i Oslo

Nye medisinske intervensjoner fordrer at kunnskapsgrunnlaget er på plass. Vi ønsker å vite at den medisinske intervensjonen vil ha de ønskede resultater, noe vi kan få svar på gjennom mange og gjentatte gode randomiserte, kontrollerte studier. Grundige kunnskapsoppsummeringer av disse studiene kan gi oss presise svar på hvordan intervensjonen virker i praksis og sørge for at vi kan tilby pasienter trygge og velutprøvde medikamenter og behandling.

Ideelt sett skulle vi ønsket tilsvarende evidensgrunnlag for store reformer og organisasjonsendringer. Det kan virke ufattelig at man setter i gang med omfattende omstruktureringer uten noen klar evidens. I et forsøk på å oppsummere kunnskapen om effekter av sykehussammenslåinger (1) ble det konkludert med at «sammenslåing av tidligere selvstendige sykehus kan gi en kostnadsreduksjon på ti prosent og bedre kvalitet [...]» (2).

Jeg ønsker i denne kronikken å vise at organisasjonsstudier inneholder viktige fortolkninger som blir borte i slike oppstillinger. Min oppfatning er at den internasjonale litteraturen om effekter av sykehusfusjoner ikke er konkluderende (3-6) - det vil si at resultatene spriker og effektene ikke er signifikante. Litteraturen peker oftere i retning av at fusjoner er en mislykket strategi fordi de så sjelden oppfyller fusjonenes mål og har så mange ikke-intenderte effekter (7-9).

Litteraturen er ikke entydig og avdekker det mangfoldet fusjoner er i seg selv og betydningen av ulike kontekster (10). Til dels preges også litteraturen av ulik nasjonal vektlegging og av at de ulike helsesystemene har ulike utfordringer. Her vil jeg analysere sju artikler som ofte går igjen i ulike oppsummeringer $(1,11)$ (tab 1) og vise at disse kan gi opphav til ulike tolkinger.

\section{Effekt av sykehusfusjoner i litteraturen}

I artikkelen av Connor og medarbeidere er det særlig konkurranseaspektet som frem- heves (12). I USA er man redd for at store sykehus lager monopoler og presser prisene opp. Connor og medarbeidere analyserer ulike typer sykehusfusjoner for å se om noen typer presser prisene mer opp enn andre. Hovedfokuset er å se på fusjoner i sykehustette områder versus fusjoner i mindre sykehustette områder. I artikkelen konkluderer de med at kostnadsgevinsten av fusjoner er marginal: «These findings indicate that cost savings and consumer benefits from hospital mergers in more concentrated market areas are marginal or even negative. This provides empirical justifications for closer antitrust review of hospital mergers in more concentrated market areas» $(12$, s. 68).

Også Spang og medarbeidere ser primært på konkurranseaspektet i USA (13). De foretar en reanalyse av de samme dataene som Connor og medarbeidere bruker (12), men utvider analyseperioden. De viser at lavere kostnadsvekst først og fremt er knyttet til høy konkurranse mellom sykehus. «We find that the presence and extent of these savings varied based on market and hospital condition. However, our findings suggest that cost and price savings resulting from mergers may be smaller than estimated in earlier studies, especially through our comparison of merging hospitals with their rivals» $(13$, s. 150).

Alexander og medarbeidere har som hovedformål å se på endringsomfang (14). Deres omfattende artikkel omhandler 94 sykehusfusjoner i USA i perioden 1982-89. Kun fusjoner som omfatter to sykehus er inkludert i studien. Det primære målet for analysen er å se på betydningen av ulike typer fusjoner. Størrelsen på sykehusene, eierskapsforhold og tidspunkt for fusjonen antas å ha betydning. Gevinst her blir omtalt som hvor store endringer som blir gjennomført. Fusjoner mellom sykehus av lik størrelse gir mest endringer. Resultatene viser også at det er en tendens til at fusjoner kan snu en negativ kostnadsutvikling. Alexander og medarbeidere gir en grundig fortolkning av funnene, og konkurranseelementet trekkes frem som sentralt for suksess.

I en annen amerikansk studie viser Dranove \& Linderoth betydningen av over- fladiske eierfusjoner sammenliknet med dyptgripende fusjoner som også omfatter funksjonsfordeling. Ved omfattende fusjoner kan det oppnås en kostnadsreduksjon på $14 \%$ i forhold til en annen type mindre effektiv fusjon (11). I artikkelen sammenliknes kun ulike sykehusfusjoner, man ekskluderer ikke-fusjonerte sykehus.

En annen studie av Dranove omfatter potensielle skalafordeler ved 302 ikke-medisinske enheter (15). Ikke-medisinske enheter er ofte slike vi assosierer med stordriftsfordeler og hvor vi vil forvente klare skalaeffekter. Han analyserer 14 ulike typer og viser at det kun vil være de aller minste sykehusene (under 136 senger) som vil kunne ha skalafordeler med å få større ikkemedisinske serviceenheter. Det er særlig personalavdeling, økonomi, IT, kantine, vask og vaskeri som gir skalafordeler. Dranove konkluderer: «Even if the merged hospital fully exploited available economies of scale in non-revenue producing cost centers, the mergers would leave consumers worse off if the merging hospitals were to raise prices by as little as $0.5 \%$ The hospitals involved should point to other possible efficiencies to justify the mergers» $(15$, s. 70$)$.

I en britisk artikkel diskuterer Fulop og medarbeidere ikke-intenderte effekter og de uklare målene for fusjoner. Dette er primært en kvalitativ artikkel basert på intervjuer, men de har også med noen kvantitative mål (16). I konklusjonen skriver de: «Important unintended consequences need to be accounted for when mergers are planned. Mergers can cause considerable disruption to services, and require greater management support than previously acknowledged» (16, s. 246).

Et gjennomgående funn i litteraturen er betydningen av nasjonal kontekst. Sentralt for studiene fra USA er at amerikanske sykehus inngår i konkurranse med hverandre, der prisreduksjon versus monopoldanning konstant er et tema. Et annet moment som viser betydningen av nasjonal kontekst og gjør sammenlikning vanskelig, er at amerikanske sykehus drives med relativt lav beleggsprosent. De aksepterer ikke ventelister av frykt for at pasientene da skal gå til konkurrenten. Lavere beleggsprosent gjør sykehusavdelingene mer fleksible. 
Av den grunn kan de lettere gjennomføre og ha incitament til fusjon. Nordiske sykehus drives med mer enn $100 \%$ belegg (korridorpasienter), noe som gjør avdelingene svært lite fleksible. Det er små marginer før arbeidsprosesser stopper opp og effektiviteten synker. Konklusjonen er at det er vanskelig å overføre funn fra artikler som omtaler utenlandske fusjoner direkte uten en nærmere fortolkning av kontekst.

I samarbeid med Terje Hagen har jeg studert effekter av sykehusfusjoner i Norge i perioden 1992-2000. Studien tar for seg effektivitetsutviklingen ved alle norske sykehus i perioden og konkluderer med at sykehus som fusjonerte, fikk en signifikant lavere kostnadseffektivitet på 2-2,8\% (4).

I en av de tidligere nevnte kunnskapsoppsummeringene (1) av disse sju studiene konkluderes det med at «Sammenslåing av sykehus kan gi en kostnadsreduksjon på om lag $10 \%$ hvis prosessen fører til reell sammensmelting av organisasjonene med felles organisasjonskultur og riktigere dimensjonering av tjenestetilbudet» (1, s. 904). Det fremgår ikke klart i artikkelen hvordan de kom frem til tallet $10 \%$. Jeg har prøvd ulike utregninger, men lander på at de må ha tatt ett gjennomsnitt av de effektene de mener disse sju artiklene viser: $(30+7+10+10+$ $5+14$ minus 2,5$) / 7=10,5$. Hvis dette er tilfellet, er denne metoden i seg selv svært tvilsom. Min gjennomgang av disse sju studiene viser at de er svært forskjellig med henblikk på fokus, problemstillinger, hva de måler, hvor mange enheter som inngår, tidsperiode og tolkinger.

\section{Hva er det man måler?}

Et sentralt diskusjonstema omkring litteratur om fusjoner er hvorvidt man måler effekter av faktiske fusjoner eller ser på potensielle effekter. I økonomisk litteratur er det vanlig å modellere for potensielle effekter. Vi kan da skrelle vekk prosesseffekter og konsentrere oss om innholdseffekter. Dette er ikke evidens, men kan brukes for å si noe om mulig potensial. Ulempen er om disse studiene brukes ukritisk i politikkutforming.

En nylig publisert artikkel fra Danmark estimerer potensielle effekter av fusjoner basert på antakelser om skalafordeler (5). Kristensen og medarbeidere konkluderer med at det ved de minst effektive danske sykehus er et stort potensial for å forbedre den tekniske effektiviteten, men at en rekke av de fusjonene som er planlagt i Danmark vil være for store (diseconomies of scale). Derimot mener de at det vil kunne være gevinster å hente ved å samle tjenester i spesialiserte enheter (economies of scale).

Dette er en spennende studie, særlig fordi den omfatter sykehus i en kontekst som likner mer på norske forhold. Men det er nødvendig å påpeke at dette er funn basert på økonomisk modellering med en rekke forutsetninger. I vår studie av norske sykehus går også vi videre $\mathrm{i}$ våre fortolkninger og antyder at det kan være gevinst å hente hvis fusjonene er mer dyptgripende og omfatter reduksjon av akuttfunksjoner.

Konklusjonen til dem som har uttalt seg om dette i Norge, er også basert på slike antakelser og er langt mer vag og normativ enn den er blitt fremstilt i mediene (2). Konklusjonen inneholder et «hvis». Det er sjelden at fusjoner ender slik dette hvis-et

Tabell 1 Oversikt over sju orginalartikler som har inngått i tidligere kunnskapsoppsummeringer om sammenslåinger av sykehus

\begin{tabular}{|c|c|c|c|c|c|}
\hline Forfatter(e) & Land & Metode & Antall enheter & Analyseperiode & Konklusjon \\
\hline $\begin{array}{l}\text { Kjekshus } \\
\text { \& Hagen } 2007\end{array}$ & Norge & $\begin{array}{l}\text { DEA-analyse, Panel- } \\
\text { data, Multippel regre- } \\
\text { sjons-analyse med } \\
\text { «fixed effects» }\end{array}$ & $\begin{array}{l}53 \text { sykehus (17 fusjo- } \\
\text { nerte sykehus) }\end{array}$ & $1992-2000$ & $\begin{array}{l}\text { Sammenslåing av sykehus i 1990-årene reduserte } \\
\text { kostnadseffektiviteten til sykehus med } 2-2,8 \% \text {. } \\
\text { Imidlertid ser det ut til at mer radikale sammen- } \\
\text { slåinger som også omfatter redusert akuttbered- } \\
\text { skap kan gi en bedret kostnadseffektivitet }\end{array}$ \\
\hline Alexander et al. & USA & $\begin{array}{l}\text { Multippel paneldata- } \\
\text { design }\end{array}$ & $\begin{array}{l}470 \text { sykehus ( } 184 \\
\text { fusjonerte sykehus) }\end{array}$ & $1982-89$ & $\begin{array}{l}\text { Kun fusjoner som omfattet to sykehus var inklu- } \\
\text { dert i studien. Sammenslåinger av sykehus av } \\
\text { samme størrelse ga større sannsynlighet for } \\
\text { større endringer }\end{array}$ \\
\hline Connor et al. & USA & Bivariat analyse & $\begin{array}{l}3500 \text { sykehus ( } 244 \\
\text { fusjonerte sykehus) }\end{array}$ & $1986-94$ & $\begin{array}{l}\text { Fusjonerte sykehus hadde } 7 \% \text { lavere prisvekst } \\
\text { enn sykehus som ikke fusjonerte. Sykehus som } \\
\text { fusjonerte i mindre konkurranseutsatte områder } \\
\text { med få sykehus hadde en prisøkning på sine tje- } \\
\text { nester sammenliknet med sykehus som fusjo- } \\
\text { nerte i områder med mange sykehus og i sterk } \\
\text { konkurranse }\end{array}$ \\
\hline Dranove & USA & $\begin{array}{l}\text { Semiparametrisk } \\
\text { analyse } \\
\text { av skalafordeler }\end{array}$ & $\begin{array}{l}302 \text { ikke medisinske } \\
\text { enheter (14 ulike } \\
\text { tjenester) }\end{array}$ & 1992 & $\begin{array}{l}\text { Et sykehus med ca. } 200 \text { senger kan potensielt få } \\
6 \% \text { lavere kostnader til ikke-medisinske service- } \\
\text { tjenester per sykehusopphold sammenliknet med } \\
\text { et sykehus med ca. } 136 \text { senger og } 32 \% \text { lavere enn } \\
\text { sykehus med } 100 \text { eller færre senger. Ingen skala- } \\
\text { fordeler forventes for sykehus med mer enn } 200 \\
\text { senger }\end{array}$ \\
\hline Spang et al. & USA & $\begin{array}{l}\text { Longitudinell bivariat } \\
\text { analyse }\end{array}$ & $\begin{array}{l}1767 \text { sykehus ( } 204 \\
\text { fusjonerte sykehus) }\end{array}$ & $1989-97$ & $\begin{array}{l}\text { Lavere prisvekst hos sykehus som fusjonerte, men } \\
\text { effekten varierte med markedsituasjonen. Fusjo- } \\
\text { nerte sykehus hadde 16,6 \% lavere kostnadsvekst } \\
\text { og } 11,9 \% \text { lavere prisvekst sammenliknet med } \\
\text { ikke-rivaliserende ikke-fusjonerte sykehus. Men } \\
\text { i områder med liten konkurranse hadde fusjonerte } \\
\text { sykehus marginalt høyere kostnadsutvikling sam- } \\
\text { menliknet med ikke-fusjonerte sykehus }\end{array}$ \\
\hline Fulop et al. & England & $\begin{array}{l}\text { Dybdeintervjuer } \\
\text { og dokumentstudier }\end{array}$ & $\begin{array}{l}96 \text { dybde-intervjuer } \\
\text { med styremedlem- } \\
\text { mer, ledere, klinikere } \\
\text { og representanter fra } \\
\text { ulike helseetater }\end{array}$ & $1998-99$ & $\begin{array}{l}\text { Ikke-intenderte konsekvenser av sammenslåinger } \\
\text { må tas i betraktning når fusjoner planlegges. } \\
\text { Sammenslåinger kan forårsake store forstyrrelser } \\
\text { i tjenestene og kreve større ledelsesmessige } \\
\text { utfordringer enn tidligere antatt }\end{array}$ \\
\hline $\begin{array}{l}\text { Dranove } \\
\text { \& Linderoth }\end{array}$ & USA & $\begin{array}{l}\text { Multippel regresjons- } \\
\text { analyse, pseudofusjoner }\end{array}$ & $\begin{array}{l}244 \text { fusjonerte syke- } \\
\text { hus }\end{array}$ & $1988-2000$ & $\begin{array}{l}\text { Kun fusjoner som omfattet to sykehus var inklu- } \\
\text { dert i studien. Ved omfattende fusjoner kan det } \\
\text { oppnås en kostnadsreduksjon på } 14 \% \text { i forhold } \\
\text { til en annen mer overfladisk fusjon }\end{array}$ \\
\hline
\end{tabular}


forutsetter. Det er en rekke forhold i Norge som gjør at det ikke blir oppfylt. Jeg tolker litteraturen dit hen at vellykkede fusjoner er fusjoner mellom to (flere enn to er som oftest ikke vellykket) små (under 200 senger), men likeverdige sykehus i et område med stor sykehustetthet og stor konkurranse. Sykehusene må dessuten inngå i en full fusjon med funksjonsfordeling (i praksis at ett sykehus legges ned og det andre bygges ut). Videre er det en forutsetning at det bevilges betydelige ombyggingsmidler og at man får til de omfattende endringene innen ett til to år.

Soki Choi, som har studert fusjonsprosessen i Stockholm, legger til betydningen av «hybridisering» - at man får mobilisert de ansatte og at beslutningsprosessen er motivert ut fra faglige mål (17).

Konklusjonen er at dette er en tematikk som ikke egner seg for en kjapp kunnskapsoppsummering. I denne sammenheng er det først og fremst snakk om artikler der funn fortolkes. Det er fortolkningene som her er spennende. Tallene i seg selv er for usikre og krever mange forbehold.

Fusjonsprosessen i Oslo universitetssykehus har utviklet seg til en skyttegravskrig hvor det er mye følelser. Det er et ønske om fakta, men forskning på sykehusfusjoner er ikke konkluderende. Det betyr ikke at den ikke er relevant og nyttig. Forskningen viser kompleksiteten og utfordringene alle som er i fusjonsprosesser står overfor. Særlig når det inngår flere sykehus, sykehus med mange senger, sykehus med ulike kulturer, en prosess uten ekstrabevilgninger og i en kontekst uten konkurranse eller andre prisreduserende virkemidler. Dette er basert på min tolking av de samme artiklene andre har lest. Jeg anbefaler andre til å gå til originallitteraturen og gjøre sine egne fortolkninger.

\section{Lars Erik Kjekshus (f. 1968)}

er dr.polit. i statsvitenskap, førsteamanuensis i organisasjon og ledelse og forskningsleder ved Avdeling for helseledelse og helseøkonomi, Institutt for helse og samfunn, Det medisinske fakultet, Universitetet i Oslo.

Ingen oppgitte interessekonflikter.

\section{Litteratur}

1. Ingebrigtsen T. Helseøkonomiske effekter av syke hussammenslåinger. Tidsskr Nor Legeforen 2010 130: $940-2$.

2. Ingebrigtsen T, Hansen OC, Stiernstedt G. Alle må stille opp. Aftenposten 8.10.2011.

3. Ferrier GD, Valdmanis VG. Do mergers improve hospital productivity? J Oper Res Soc 2004; 55 : 1071-80.

4. Kjekshus LE, Hagen TP. Do hospital mergers increase hospital efficiency? Evidence from a National Health Service country. J Health Serv Res Policy 2007; 12: 230-5.

5. Kristensen T, Bogetoft P. Pedersen KM. Potential gains from hospital mergers in Denmark. Health Care Manage Sci 2010; 13: 334-45.

6. Harris J, Ozgen H, Ozcan Y. Do mergers enhance the performance of hospital efficiency? J Oper Res Soc 2000: 51: 801-11.
7. Burns LR, Pauly MV. Integrated delivery networks: a detour on the road to integrated health care? Health Aff (Millwood) 2002; 21: 128-43.

8. Fulop N, Protopsaltis G, King A et al. Changing organisations: a study of the context and processes of mergers of health care providers in England. Soc Sci Med 2005; 60: 119-30.

9. Posnett J. Is bigger better? Concentration in the provision of secondary care. BMJ 1999; 319: 1063-5.

10. Lynk WJ. Nonprofit hospitals mergers and the exercise of market power. J Law Econ 1995; 38 437-61.

11. Dranove D, Lindrooth R. Hospital consolidation and costs: another look at the evidence. J Health Econ 2003; 22: 983-97.

12. Connor RA, Feldman RD, Dowd BE et al. Which types of hospital mergers save consumers money? Health Aff (Millwood) 1997: 16: 62-74.

13. Spang HR, Bazzoli GJ, Arnould RJ. Hospital mergers and savings for consumers: exploring new evidence. Health Aff (Millwood) 2001; 20: 150-8.

14. Alexander JA, Halpern MT, Lee SY. The short-term effects of merger on hospital operations. Health Serv Res 1996; 30: 827-47.

15. Dranove D. Economies of scale in non-revenue producing cost centers: implications for hospital mergers. J Health Econ 1998; 17: 69-83.

16. Fulop N, Protopsaltis G, Hutchings A et al. Process and impact of mergers of NHS trusts: multicentre case study and management cost analysis. BMJ 2002; 325: 246-52.

17. Choi S. Competing logics in hospital mergers. The case of the Karolinska University Hospital. Stockholm: Medical Management Centre, Department of Learning, Informatics, Management and Ethics, Karolinska Institutet, 2011.

Mottatt 13.10. 2011, første revisjon innsendt 9.11. 2011, godkjent 17.11. 2011. Medisinsk redaktør Anne Kveim Lie. 